\title{
A Stepwise Analysis of Production Returns and Cost Distribution for Chinese Cabbage Produced Under Irrigation in South Africa
}

\author{
B. Taruvinga ${ }^{1}$, P. Ndou ${ }^{1}$, T. D. Ramusandiwa ${ }^{1}$, K. Seetseng ${ }^{1} \&$ C. P. du Plooy ${ }^{1}$ \\ 1 Agricultural Research Council-Vegetables and Ornamental Plants (ARC-VOP), Crop Science Division, \\ Pretoria, South Africa \\ Correspondence: P. Ndou, Agricultural Research Council-Vegetables and Ornamental Plants (ARC-VOP), Crop \\ Science Division, Private Bag X293, Pretoria 0001, South Africa. Tel: 27-12-808-8000. E-mail: \\ ndoup@arc.agric.za
}

Received: August 18, 2020

Accepted: November 3, 2020

Online Published: December 15, 2020

doi:10.5539/jas.v13n1p88

URL: https://doi.org/10.5539/jas.v13n1p88

\begin{abstract}
Cultivation of indigenous crops for food and nutritional security has emerged as a topic of interest in South Africa. Commercial cultivation of indigenous crops is promoted especially among smallholder farmers because of their nutritional value and their ability to adapt to marginal soil and climatic conditions. Support for commercial production of specific crops among farmers necessitates the need for optimum use of inputs in production. In order to evaluate optimum input use in production, this study established the profitability and production costs of one of the indigenised leafy vegetables in South Africa, Chinese cabbage, using gross margin analysis. Production costs and profitability evaluations are fundamental tools for analysing cash flow and investment options. The study was based on field trials on different levels of fertilizer (NPK application). The results of the study show that at low production level $\left(10.1 \mathrm{t} \mathrm{ha}^{-1}\right)$, gross income is less than total variable costs (TVC), resulting in a negative gross margin. A movement from low production to medium production $\left(26.1 \mathrm{tha}^{-1}\right)$ results in an increase in gross margin, from -R16,664.19 to R29,091.99. The highest gross margin of R82,807.07 is obtained at high production level $\left(44.5 \mathrm{t} \mathrm{ha}^{-1}\right)$. The study supports an interdisciplinary evaluation approach (agronomy and economics) when analysing field trials.
\end{abstract}

Keywords: yield, inputs, gross margin, revenue

\section{Introduction}

The global agricultural sector faces increasing pressure to produce additional volumes of food to meet the rising demand, resulting from growth in population, urbanisation and rising per capita incomes. The irony is, increasing food production is expected to take place amidst several challenges such as climate change, limited investment, intense competition and volatile market conditions, particularly in developing countries (Dobermann \& Nelson, 2013; Elferink \& Schierhorn, 2016). Two options that are available for increasing food production are clearing additional land for agriculture or intensifying production on existing land. However, the former is not always preferred because it is not always feasible and is associated with several high ecological and social trade-offs (Tilman et al., 2011). As a result, farmers are often inclined to adopt production methods that optimise returns on inputs.

Several approaches for increasing food production and productivity to meet rising food demands have always been under discussion (Dobermann \& Nelson, 2013; Ebert, 2014; Tilman et al., 2011). One of the approaches that has gained popularity involves support for crop diversification and investment in new and underutilised crops, rather than over-reliance on a few staple crops, which can be unsustainable in the long run (Ebert, 2014). In line with supporting underutilised crops, cultivation of indigenous crops for food and nutritional security, has emerged as a topic of interest in South Africa. Commercial production of indigenous crops (grains, vegetables and fruit crops) is promoted in the country (DAFF, 2013; Macaskill, 2017).

In general, indigenous crops are regarded as highly nutritious, therefore, a valuable component for attaining nutritional security (Keatinge et al., 2011). Apart from their nutritional value, most of these indigenous crops are hardy and adapt to marginal soil and climatic conditions (Hughes \& Ebert, 2013). Regardless of their benefits, production of indigenous crops is often limited to smallholder farmers, as their consumption is generally limited to specific groups of people (DAFF, 2013; Stamp et al., 2012). In addition, some species have not yet been 
considered for cultivation, as they can be harvested from the wild. The argument presented forth is that, indigenous crops are required in small amounts; therefore, the quantities harvested from the wild should be sufficient (Mavengahama, 2013). In contrary, there are higher prospects of an increase in consumption of indigenous crops in South Africa, owing to increased promotion. For instance, several universities (such as University of Venda, University of the Free State and Stellenbosch University) in South Africa are jointly implementing Nutrition Education Intervention Programmes (NEIPs) that encourage the consumption of indigenous foods, and some positive indicators in consumption are already showing. A study carried out by Mushaphi et al. (2017), in Limpopo Province indicates that consumption of a number of indigenous vegetables increased considerably after the implementation of the NEIP. There was a significant increase in the percentage of children who consumed indigenous vegetables such as black jack (Bidens pilosa; $[8.2 \%$; 37.6\%]), spider flower (Cleome gynandra; [6.5\%; 34.3\%]) and wild-jute plant (Corchorus hirstirus or Corchorus olitorius; $[9.1 \% ; 37.5 \%])$ at $95 \% \mathrm{CI}$ for the percentage difference between baseline and post-intervention (Mushaphi et al., 2017). The increase in consumption necessitates an increase in supply through cultivation, or else there will be increased pressure on wild species possibly leading to extinction of such species (Maseko et al., 2018).

Efforts of commercialising indigenous vegetables in South Africa have been directed towards smallholder farmers because of their comparative advantage. Smallholder farmers in South Africa have a strong technical base of knowledge for producing indigenous crops (African Centre for Biodiversity, 2017). Most of these farmers have always been involved in cultivating the crops, although on a relatively small scale, mostly for household consumption (Ebert, 2014). Indigenous crops are common among smallholder farmers due to their cultural value, as a source of food and medicine, and because the crops can be produced with relatively few and low capital inputs. The crops are preferred because they have low capital risk for smallholder farmers, given the challenges of lack of resources among these farmers (African Centre for Biodiversity, 2017; DAFF, 2013). Nonetheless, commercialisation of indigenous vegetables in South Africa is on an infancy level and there is still limited research on productivity and economic returns of these crops (DAFF, 2013; Macaskill, 2017). The current research sought to contribute to literature by analysing returns and costs associated with producing Chinese cabbage, one of the indigenous leafy vegetables in South Africa. The study sought to make economic deductions using results of on-farm agronomic experiments.

Chinese cabbage, also known locally as Mustard spinach or Mutshaina, is an indigenised leafy vegetable in South Africa, but originated in China. It is a winter vegetable, which has a short growing season; taking between 6 and 11 weeks from sowing to the end of the vegetative stage (Maseko et al., 2017; van Averbeke et al., 2007). Cultivation of Chinese cabbage in the country originated in Vhembe District, in the north of Limpopo Province, however its cultivation is spreading rapidly into other areas of Limpopo and other provinces such as Mpumalanga, KwaZulu-Natal, Gauteng and North West (Maseko et al., 2017; Tshikalange \& van Averbeke, 2006). This vegetable is widely produced for own consumption and marketing purposes by smallholder farmers (Manyelo et al., 2015; Maseko et al., 2018).

Preceding studies on the nutritive composition of Chinese cabbage identify the vegetable as a valuable source of nutrients. It contains dietary fibre, beta-carotene, vitamin C, vitamin K, thiamine, riboflavin, vitamin B6, folate and mineral nutrients (Podsedek, 2007; van Jaarsveld et al., 2014; van Wyk, 2005). Relative to white cabbage (Brassica oleracea L. var. capitate) which is one of the most commonly consumed leafy vegetable among native people in South Africa; Chinese cabbage is richer in nutrients per unit fresh mass. For instance, a $100 \mathrm{~g}$ of fresh white cabbage contains $55 \mathrm{~g}$ calcium, $0.8 \mathrm{mg}$ iron and $280 \mu \mathrm{g}$ beta-carotene, whereas a $100 \mathrm{~g}$ of fresh Chinese cabbage contains $102 \mathrm{~g}$ calcium, $2.6 \mathrm{mg}$ iron and 2,305 $\mu \mathrm{g}$ beta-carotene (van Averbeke et al., 2007). In addition to the nutritional benefits, Chinese cabbage has some medicinal properties; its flowers and leaves attached to the peduncle are used to regulate high blood pressure (van Averbeke et al., 2007). These benefits position Chinese cabbage as a potentially suitable vegetable for promoting food and nutrition security in South Africa, especially among the rural poor.

Production of Chinese cabbage will likely increase in South Africa, owing to growth in agronomic research and development, benefit awareness, promotion and commercialisation efforts by several stakeholders. Such efforts include promotion of indigenous crops cultivation by Provincial Departments of Agriculture and Rural Development (DAFF, 2018) research on indigenous crops by the Agricultural Research Council (ARC, 2018) and Nutrition Education Intervention Programmes by several universities in South Africa (Mushaphi et al., 2017). Increasing production of vegetables among farmers necessitates the need for optimum use of inputs for increased benefits. Several agronomic studies have been carried out on the vegetable (Maseko et al., 2017; Okorogbona et al., 2011; Tshikalange \& van Averbeke, 2006; van Averbeke \& Netshithuthuni, 2010), however, the research omitted the component of economic and financial analyses. Generally, there is limited literature highlighting the 
economic and financial implications associated with producing Chinese cabbage, as well as the movement of the crop along the value chain after production, thus necessitating the need to carry out such research. An analysis of economic and financial aspects is important for evaluating viability and sustainability in production. In addition, economic analysis offers an overview of costs and profitability to the producers, thereby allowing them to make informed production decisions and adjustments that support cost efficiency (Ocneanu \& Bucşă, 2014).

\section{Methodology}

The study followed a quantitative approach, where it focussed on analysing returns and costs of Chinese cabbage production, by making use of data on yield, produce price, level of inputs utilised in production and input prices. The research combined agronomic evaluations, statistical analysis and economic analyses because it sought to eliminate the traditional barrier and the limitations that are created by separating agronomic evaluations from economic analyses. For example, by basing only on agronomic data, technical relationships are used to determine the technical optimum. However, by introducing economic aspects of pricing and marketing, an economic optimum can be established which could be different from the technical optimum (Kirway et al., 2003). As such, the usefulness of the results of agronomic research experiments can be greatly enhanced by applying relevant economic analysis. It is vital that agricultural scientists and agricultural economists jointly evaluate experiments to establish both agronomic and economic viability.

Data for yield and the level of inputs utilised in production was collected from the field trials on different levels of fertilizer (NPK) that were carried at the Agricultural Research Council-Vegetable and Ornamental Plants (ARC-VOP) at Roodeplaat, South Africa, during the winter seasons (May-August) in 2016 and 2017. Seedlings were prepared in 200-hole polystyrene trays, where Mustard spinach seeds (Cultivar 'Florida Broadleaf', Starke Ayres seed Pty. Ltd., South Africa) were sown in trays filled with a commercial growth medium, Hygromix (Hygrotech Seed Pty. Ltd., South Africa) and covered with a thin layer of vermiculite after sowing. Seedlings were transplanted 28 days after sowing into an open field using a plant spacing of $30 \mathrm{~cm} \times 30 \mathrm{~cm}$ (thus same plant density). Fertilizer was applied during transplanting. The different fertilizer rates were as follows: 0,75 , 150,225 and $300 \mathrm{~kg} \mathrm{~N}^{-1}{ }^{-1}$ (where the source was limestone ammonium nitrate [LAN (28\% N)]; 0, 100, 200 and $300 \mathrm{~kg} \mathrm{Pha}^{-1}$ [source single superphosphate $\left.(12.5 \% \mathrm{P})\right] ; 0,60$ and $120 \mathrm{~kg} \mathrm{~K} \mathrm{ha}^{-1}$ (source potassium chloride [KCl $(50 \% \mathrm{~K})]$. A randomised complete block design with four replicates was used in this experiment. Each plot size was $3 \mathrm{~m} \times 1.5 \mathrm{~m}$ and each experiment had 60 plots. Harvesting commenced after 30 days of transplanting, and thereafter harvesting was done at 14-days intervals. In total there were 4 harvests. Harvesting was done by removing the outer matured leaves and leaving four small inner leaves. Immediately after harvesting, the leaf fresh mass of ten data plants per replicate were measured to get the yield.

A list of inputs used in production was compiled from field trials, and varying levels of inputs in different fertilizer treatments were matched with the yield. Trial data on yield was adjusted to accommodate wastes and losses resulting from household consumption, donations, gifts and breakages and production anomalies. According to IWMI (2010), approximately $20 \%$ of marketable yield of fresh vegetables is not marketed in a commercial production setup. Therefore, the yield data in the analysis was adjusted to account for $80 \%$ of total production. Data for two seasons was utilised in order to provide reliable information by overcoming the one-year production aberration. Data for both input and produce prices was obtained from the markets, where the present monetary values for 2016 and 2017 were used. Various prices were obtained from different markets, but average prices of inputs and produce prices were utilized for analysis.

Gross Margin (GM), also known as Average returns above variable costs (RAVC) analysis was adopted to determine the profitability of Chinese cabbage production under irrigation. Gross margin analysis is a useful tool for measuring profitability of an enterprise. It is important in cash flow planning and determining the relative profitability of farm enterprises (Rural Solutions SA, 2013). GM analysis involves the evaluation of the operational costs and returns to production per hectare for a given period (usually per year or per cropping season). It measures the difference between gross revenue and a summation of variable costs (Visagie \& Ghebretsadik, 2005). When calculating gross margins, fixed (overhead) costs are not considered because they are always incurred regardless of the level of the enterprise undertaken (Rural Solutions SA, 2013). Fixed costs can also be overlooked when comparing field trials that used the same fixed inputs. In that case, fixed costs are overlooked to avoid repetition, while focus is placed on the variable costs, as they have a direct influence on the outcome (Kirway et al., 2003). Gross margin analysis is suitable for this study as it has been successfully utilised by several authors in determining profitability of enterprises (e.g., Kibirige et al., 2014; Maoba, 2016; Olujide \& Oladele, 2007). 
The formula for calculating GM is given as:

$$
G M=G R-T V C
$$

Where, $G M=$ Gross Margin $(\mathrm{R} / \mathrm{ha}) ; G R=$ Gross Revenue $(\mathrm{R} / \mathrm{ha}) ; T V C=$ Total Variable Costs $(\mathrm{R} / \mathrm{ha})$.

When analysing the data, the levels of inputs used in production and their corresponding prices is translated into costs, while the yield and produce prices is translated into revenue. Therefore, for estimating Gross Revenue (GR), the market price of given produce is multiplied by the total yield; and for Total Variable Costs (TVC), market price of given inputs is multiplied by quantities of inputs utilised in production.

By adding these details in the GM formula, it can then be presented as:

$$
G M=\sum_{y=1}^{n} P_{y} Q_{y}-\sum_{x=1}^{n} P_{x} Q_{x}
$$

Where, $P_{y}$ is the price of produce; $Q_{y}$ is the total yield; $P_{x}$ is the price of inputs; $Q_{x}$ is the levels of inputs.

In order to cater for the $20 \%$ losses and wastes, Equation 2 is adjusted as following:

$$
G M=\sum_{y=1}^{n} P_{y} 0.8 Q_{y}-\sum_{x=1}^{n} P_{x} Q_{x}
$$

In the current study, GM analysis was applied for calculating net returns on different production levels (divided into low, medium and high production) and at a given produce price. The variable costs that were included in the study comprised of costs of land preparation, labour, growth media, seeds, water and energy, fertilizer and chemicals. However, since the trial was centred on fertilizer rates, all the other cost factors were held constant, except for fertilizer and factors that are directly influenced by changes in fertilizer combinations. The study further analysed the proportion of categorised production costs (input costs, tractor running costs and labour costs) to the total variable costs in order to identify the spread of costs per given production level. The Statistical Package for Social Science (SPSS version 24) was utilised for data analysis, and tables and charts were used to present the results.

\section{Results and Discussion}

\subsection{Fresh Leaf Yield}

The total yield per season that was utilised in the study was based on an average fresh leaf yield for two seasons (2016 and 2017), where each season had four harvests. From the trial, 60 yield results were obtained, as influenced by different fertilizer treatments (Figure 1).

The fresh leaf yield ranged between 9 and $46 \mathrm{tha}^{-1}$. The yield results observed in this study are different from preceding studies on Chinese cabbage. Maseko et al. (2017) reported that fresh leaf yields of Chinese cabbage ranged between 3.04 and $10.13 \mathrm{t} \mathrm{ha}^{-1}$, as influenced by different rates of Nitrogen. van Averbeke and Netshithuthuni (2010) reported that the optimum yield for Chinese cabbage is $39 \mathrm{t} \mathrm{ha}^{-1}$ in full irrigation (FI) and $38 \mathrm{t} \mathrm{ha}^{-1}$ in double frequency farmer (DFF) treatments. Tindall (1983) stated that fresh leaf yields of Chinese cabbage ranged between 5 and $30 \mathrm{tha}^{-1}$, subject to environmental conditions, planting density and cultivar. These differences observed in the fresh yield results possibly emanate from the differences in the trial designs, treatments under consideration and environmental conditions. 


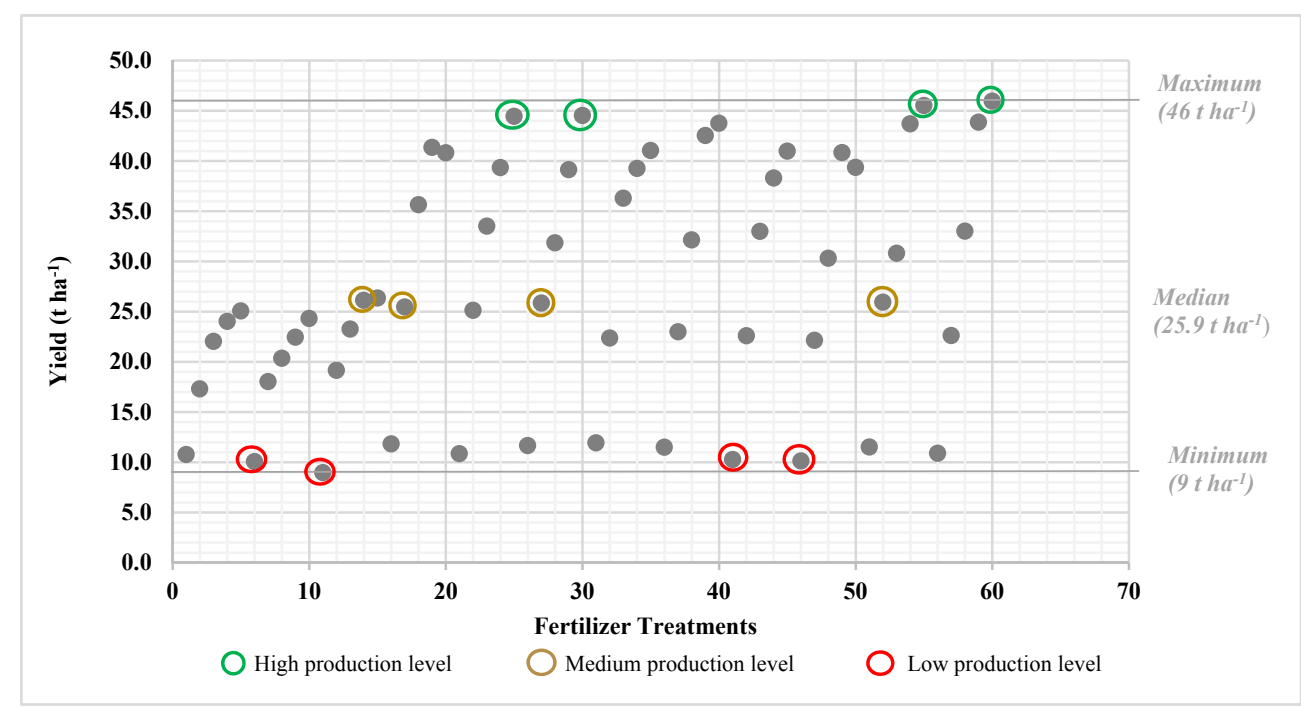

Figure 1. Yield categories for gross margin analysis

\subsection{Utilising Fresh Yield Results in Gross Margin}

The entire (60) yield results obtained from the field trials cannot be used for calculating gross margin due to the intensity of the procedure. In a way of trying to avoid the long procedure, people often resort to quick descriptive analyses that indicate maximum, minimum and mean values. The problem of descriptive analyses in this case is that it does not provide a clear connection between yields and costs. As an example, Table 1 shows results of a quick descriptive analysis of the trial. The treatment with the minimum yield is not the same with the least costs or least gross margin. Also the one with the highest yield is not the same with the highest costs or the highest gross margin. As such, apart from just providing information, the results in Table 1 cannot be readily used for recommending a certain level of production.

Table 1. Production returns and costs

\begin{tabular}{lllll}
\hline & Min & Max & Mean & Std. Dev. \\
\hline Yield $\left(\mathrm{t} \mathrm{ha}^{-1}\right)$ & $9 \mathrm{t}$ & $46 \mathrm{t}$ & $27.8 \mathrm{t}$ & 16.2526 \\
Gross Revenue $\left(\mathrm{ZAR} \mathrm{ha}{ }^{-1}\right)$ & $\mathrm{R} 36,000$ & $\mathrm{R} 184,000$ & $\mathrm{R} 111,200$ & 468.0344 \\
Total variable costs $\left(\mathrm{ZAR} \mathrm{ha}^{-1}\right)$ & $\mathrm{R} 57,064.19$ & $\mathrm{R} 109,768.92$ & $\mathrm{R} 78,619.55$ & 241.9142 \\
Gross Margin $\left(\mathrm{ZAR} \mathrm{ha}{ }^{-1}\right)$ & $-\mathrm{R} 36,064.19$ & $\mathrm{R} 82,807.07$ & $21,371.75$ & 336.1375 \\
\hline
\end{tabular}

In an effort to link yield and costs in gross margin analysis, a 4-step selection method was followed. The first step involved dividing production levels into low, medium and high, as informed by the minimum, median and maximum yields respectively. In the second step, four yields per production level were selected, where the yields that were closest to (and including) minimum, median and maximum yields were chosen. Thus, a total number of 12 yield levels were selected. Figure 1 summarises the first and second steps of the yield selection process.

As shown on Figure 1, the maximum, median and minimum yields were $46 \mathrm{t} \mathrm{ha}^{-1}, 25.9 \mathrm{t} \mathrm{ha}^{-1}$ and $9 \mathrm{t} \mathrm{ha}^{-1}$ respectively. Four yields $\left(46 \mathrm{t} \mathrm{ha}^{-1}, 45.5 \mathrm{t} \mathrm{ha}^{-1}, 44.5 \mathrm{tha}^{-1}\right.$ and $\left.44.5 \mathrm{tha}^{-1}\right)$ that were selected for the high production level are circled in green, whereas those selected for medium production and low production levels are circled in yellow and red respectively.

The third step involved matching selected yields to their respective fertilizer rates and these results are illustrated in Figure 2. The yields under low production level indicate the use of potassium, phosphorus or a combination of the two fertilizers in production. Nitrogen was lacking in all cases, therefore these results augment the importance of nitrogen in improving yield of Chinese cabbage (van Averbeke et al., 2012) and in promoting yield of leafy vegetables in general (Onyango, 2002). Even in a certain instant, where high levels of phosphorus (300 kg P ha ${ }^{-1}$ ) was applied without potassium and nitrogen, the yield obtained was still low $\left(10.1 \mathrm{t} \mathrm{ha}^{-1}\right)$. The results of this study also support findings from Maseko et al. (2017) reporting that all treatments that did not receive nitrogen $\left(0 \mathrm{~kg} \mathrm{~N} \mathrm{ha}^{-1}\right)$ in their experiment showed stunted growth and low yield. 


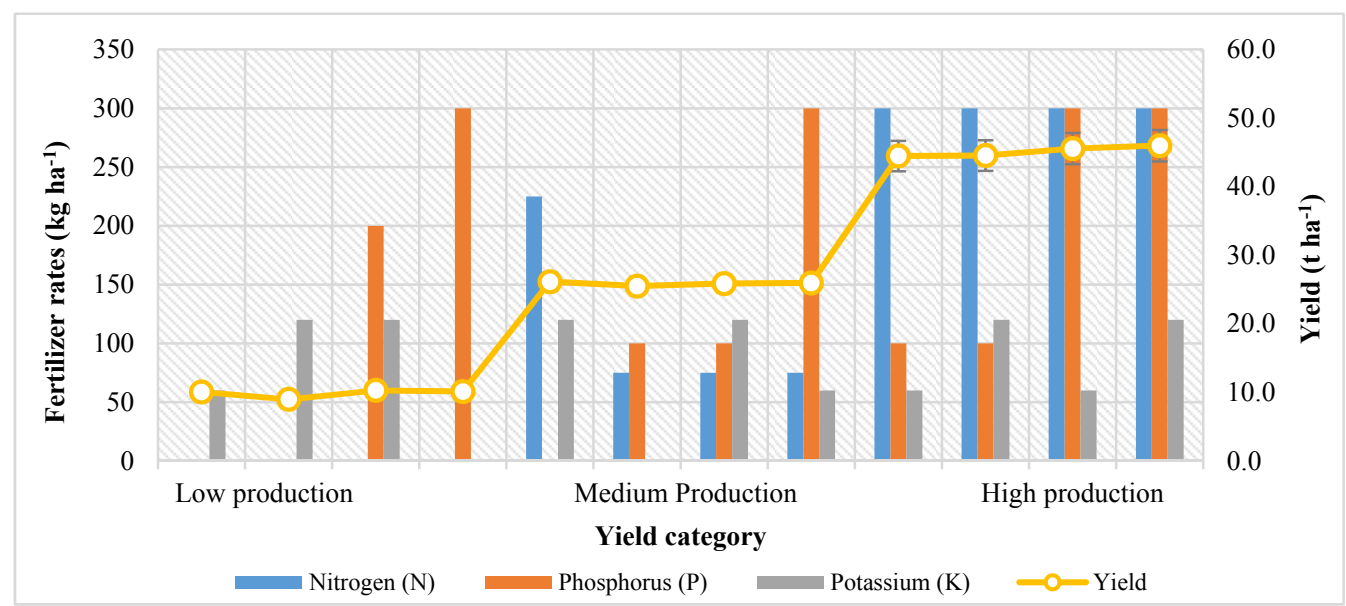

Figure 2. Influence of fertilizer rates on yield

The yield falling in the medium production level indicated combined use of at least two types of fertilizers in production, and in all instances, nitrogen was applied. In three cases, nitrogen levels of $75 \mathrm{~kg} \mathrm{~N} \mathrm{ha}^{-1}$ were applied together with different levels of phosphorus and potassium. In one instance, high levels of nitrogen $(225 \mathrm{~kg} \mathrm{~N}$ $\left.\mathrm{ha}^{-1}\right)$ was applied together with potassium only $\left(120 \mathrm{~kg} \mathrm{~K} \mathrm{ha}^{-1}\right)$. An analysis of these results indicate that an increase in nitrogen levels without increasing the other nutrients does not guarantee an increase in yield. The results of this study partly explain the reason why there was no significance difference in yield between $50 \mathrm{~kg} \mathrm{~N}$ $\mathrm{ha}^{-1}$ and $100 \mathrm{~kg} \mathrm{~N} \mathrm{ha}^{-1}$ in a study that was carried out by Maseko et al. (2017) which focussed on nitrogen levels.

The yield falling in the high production level indicated high rates of nitrogen application $\left(300 \mathrm{~kg} \mathrm{~N} \mathrm{ha}^{-1}\right)$ with different levels of phosphorus and potassium. The use of high rates of nitrogen to get high yields further supports the importance of nitrogen in the growth and development of leafy plants. All the yields in the high production level show combined use of the three types of fertilizer (NPK), thus highlighting the importance of a right combination of nutrients in production. The results on high nitrogen application $\left(300 \mathrm{~kg} \mathrm{~N} \mathrm{ha}^{-1}\right)$ in production of Chinese cabbage are in contrast to recommendations made by van Averbeke et al. (2007b), where an application rate of $188 \mathrm{~kg} \mathrm{~N} \mathrm{ha}^{-1}$ was reported as optimum for Chinese cabbage. Again, the differences are possibly due to focus on one nutrient as the study by van Averbeke et al. (2007b) was based on a pot study that utilised soil containing only traces of mineral nitrogen.

In the final step, the different fertilizer combinations that were used in production of the 12 yield levels that were selected in step 2 were costed. Table 2 illustrates the different fertilizers used in production, together with their total costs.

Table 2. Fertilizer rates and costs

\begin{tabular}{llllll}
\hline Production Level & Nitrogen $(\mathbf{N})$ & Phosphorus (P) & Potassium (K) & Yield (t/ha) & Total Costs of Fertilizers (R/ha) \\
\hline \multirow{3}{*}{ Low Production } & 0 & 0 & 60 & 10.1 & $\mathrm{R} 1416.00$ \\
& 0 & 0 & 120 & 9.0 & $\mathrm{R} 2832.00$ \\
& 0 & 200 & 120 & 10.3 & $\mathrm{R} 16272.00$ \\
Medium Production & 0 & 300 & 0 & 10.1 & $\mathrm{R} 20160.00$ \\
& 225 & 0 & 120 & 26.1 & $\mathrm{R} 7571.18$ \\
& 75 & 100 & 0 & 25.5 & $\mathrm{R} 8299.73$ \\
& 75 & 100 & 120 & 25.9 & $\mathrm{R} 11131.73$ \\
High Production & 300 & 60 & 25.9 & $\mathrm{R} 23155.73$ \\
& 300 & 100 & 60 & 44.5 & $\mathrm{R} 14454.90$ \\
& 300 & 100 & 120 & 44.5 & $\mathrm{R} 15870.90$ \\
& 300 & 300 & 60 & 45.5 & $\mathrm{R} 27894.90$ \\
\hline
\end{tabular}

The total costs of fertilizer within each production level (low, medium and high production) were compared against each other, and those bearing the least costs were selected for use in gross margin analysis. In the low production level, the option where only $60 \mathrm{~kg} \mathrm{~K} \mathrm{ha}^{-1}$ was utilized in production was chosen, as the total costs of 
fertilizer was only R1,416.00 ha ${ }^{-1}$ as compared to other options with R2,832.00 ha $\mathrm{C}^{-1}$, R16,272.00 ha ${ }^{-1}$ and R $20,160.00 \mathrm{ha}^{-1}$. In the medium production level, the combination yielding the least cost was $225 \mathrm{~kg} \mathrm{~N}^{-1}$ and $120 \mathrm{~kg} \mathrm{~K} \mathrm{ha}^{-1}$, with a total fertilizer cost of R7,571.18. In the high production level, the combination that yielded the least costs was $300 \mathrm{~kg} \mathrm{~N} \mathrm{ha}^{-1}, 100 \mathrm{~kg} \mathrm{Pha}^{-1}$ and $60 \mathrm{~kg} \mathrm{~K} \mathrm{ha}^{-1}$, with total fertilizer cost of R14,454.90 ha- ${ }^{-1}$. These costs were utilised in the gross margin analysis. The rationale behind choosing the lowest costs per production level is that producers seek to maximize profits or revenue in production (Debertin, 2012). Therefore, given that additional use of fertilizer would not significantly increase yield, producers opt for least costs per yield level. Of noteworthy, the highest yield per production level did not necessarily had the least cost. The optimum yields were $10.3 \mathrm{t} \mathrm{ha}^{-1} ; 26.1 \mathrm{t} \mathrm{ha}^{-1}$ and $46.0 \mathrm{t} \mathrm{ha}^{-1}$ for low, medium and high production levels, respectively. After considering the costs of production the following yields, $10.1 \mathrm{tha}^{-1} ; 26.1 \mathrm{t} \mathrm{ha}^{-1}$ and $44.5 \mathrm{tha}^{-1}$ were selected for low, medium and high production levels, respectively because they bore the least costs. These results indicate possible differences in economic optimum and technical optimum as identified by Kirway et al. (2003).

\subsection{Gross Margin Analysis}

Prices received by producers, often vary depending on location, type of market used, quality of produce and season. When calculating gross margin, either a range of prices or a certain price can be utilised (Rural Solutions SA, 2013). In the current study, average prices offered at formal markets were used in the calculations. Since this study looks at commercial production, the average price offered at formal markets (R5.00 per $\mathrm{kg}$ ) that absorb bulk produce was utilised in the calculations. Prices of Chinese cabbage can go as high as R10.00 per kg in informal markets. However, these prices could not be utilised in the calculations because informal markets, although largely used by smallholder farmers for marketing produce, are not reliable in ordering large quantities (Khapayi \& Celliers, 2016).

Table 3 summarises the gross margin analysis of Chinese cabbage at different production levels. At low production levels $\left(10.1 \mathrm{tha}^{-1}\right)$, gross income is less than total variable costs (TVC), resulting in a negative gross margin of -R16,664.19. A negative gross margin (loss) is undesirable to any producer because it indicates a reduction in farm income. In addition, any enterprise operating at a loss cannot sustain its operations (Debertin, 2012). Farmers operating at low production levels are vulnerable to losses because of income problems associated with low yields. A movement from low production to medium production $\left(26.1 \mathrm{t} \mathrm{ha}^{-1}\right)$ result in an increase in gross income, hence a change from negative to positive gross margin. The variable costs of production also increased with the change in production levels; nonetheless, the gains in income outweighed the costs. Furthermore, a movement from medium production to high production $\left(44.5 \mathrm{t} \mathrm{ha}^{-1}\right)$ result in a further increase in gross margin. High production level generated the highest gross margin of R82,807.07 ha ${ }^{-1}$; which is equivalent to $87.0 \%$ of the total variable costs. Positive gross margins are desired in an enterprise because they indicate the amount of money left after covering variable costs. High gross margins are ideal in an enterprise because they are an indication of financial stability and success. An enterprise with high gross margins has money to cover fixed costs, expand and invest in other operations (Debertin, 2012). The breakeven yield of 15.7 $\mathrm{t} \mathrm{ha}^{-1}$, indicate that farmers willing to realise a profit should aim to produce above this value.

Table 3. Gross margin analysis at different production levels

\begin{tabular}{|c|c|c|c|}
\hline \multicolumn{4}{|c|}{ Fresh Marketable Yield } \\
\hline & $\begin{array}{l}\text { Low Production } \\
\left(10.1 \mathrm{t} \mathrm{ha}^{-1}\right)\end{array}$ & $\begin{array}{l}\text { Medium Production } \\
\left(26.1 \mathrm{t} \mathrm{ha}^{-1}\right)\end{array}$ & $\begin{array}{l}\text { High Production } \\
\left(44.5 \mathrm{t} \mathrm{ha}^{-1}\right)\end{array}$ \\
\hline \multicolumn{4}{|l|}{ Gross Margin per Production Activity } \\
\hline Gross income per ha (at an average price of R5.00 per $\mathrm{kg}$ ) & $\mathrm{R} 40,400.00$ & $\mathrm{R} 104,400.00$ & $\mathrm{R} 178,000.00$ \\
\hline \multicolumn{4}{|l|}{ Production Activity } \\
\hline Seedling preparation & $\mathrm{R} 24,741.55$ & $\mathrm{R} 24,741.55$ & $\mathrm{R} 24,741.55$ \\
\hline Land preparation & $\mathrm{R} 5,300.00$ & $\mathrm{R} 5,300.00$ & $\mathrm{R} 5,300.00$ \\
\hline Transplanting & $\mathrm{R} 9,704.16$ & $\mathrm{R} 9,704.16$ & $\mathrm{R} 9,704.16$ \\
\hline Field maintenance (including fertilization) & $\mathrm{R} 11,130.32$ & $\mathrm{R} 18,685.50$ & $\mathrm{R} 27,319.22$ \\
\hline Harvesting & R6,188.16 & $\mathrm{R} 16,876.80$ & $\mathrm{R} 28,128.00$ \\
\hline Total variable costs (TVC) & R57,064.19 & $\mathrm{R} 75,308.01$ & R95,192.93 \\
\hline Gross margin per ha & $\underline{-R} 16,664.19$ & $\underline{\mathrm{R} 29,091.99}$ & $\underline{\mathrm{R} 82,807.07}$ \\
\hline Gross margin per kg & $-\mathrm{R} 2.06$ & $\mathrm{R} 1.39$ & $\mathrm{R} 2.33$ \\
\hline Gross margin (\%) & $-29.2 \%$ & $38.6 \%$ & $87.0 \%$ \\
\hline Breakeven yield is $15.7 \mathrm{th} \mathrm{h}^{-1}$ & & & \\
\hline
\end{tabular}




\begin{tabular}{llll}
\hline Costs Analysis per Category of Factor of Production & & & \\
Input cost per ha & $\mathrm{R} 26,411.55$ & $\mathrm{R} 32,566.73$ & $\mathrm{R} 39,450.45$ \\
Input cost per kg yield & $\mathrm{R} 3.27$ & $\mathrm{R} 1.56$ & $\mathrm{R} 1.11$ \\
Input cost (\%) of TVC & $46.3 \%$ & $43.2 \%$ & $41.4 \%$ \\
Tractor-running costs per ha & $\mathrm{R} 4,500.00$ & $\mathrm{R} 4,500.00$ & $\mathrm{R} 4,500.00$ \\
Tractor-running costs per kg & $\mathrm{R} 0.56$ & $\mathrm{R} 0.22$ & $\mathrm{R} 0.13$ \\
Tractor-running costs (\%) of TVC & $7.9 \%$ & $6.0 \%$ & $4.7 \%$ \\
Labour costs per ha & $\mathrm{R} 26,152.64$ & $\mathrm{R} 38,241.28$ & $\mathrm{R} 51,242.48$ \\
Labour costs per kg & $\mathrm{R} 3.24$ & $\mathrm{R} 1.83$ & $\mathrm{R} 1.44$ \\
Labour costs (\%) of TVC & $45.8 \%$ & $50.8 \%$ & $53.8 \%$ \\
\hline
\end{tabular}

Note. The calculations made represent the costs to produce Chinese cabbage up to harvesting: calculations did not account for sorting, packaging, transportation and marketing costs.

Average yield and prices were utilised in the study, however it is a known fact that these economic factors are reliable to change. For instance, different yields can be obtained even if the same quantities of inputs are applied, due to other factors such as management and climate. Prices of both inputs and produce are likely to vary based on the market conditions and location. Changes in yield and prices will definitely have an influence on the gross margin, implying that as the prices change, farmer recommendations would also change. A sensitivity analysis can be used to test the ability of a given recommendation to withstand changes (Kirway et al., 2003).

A simplified sensitivity analysis is presented on Table 4. It shows the changes in gross margin if the price of Chinese cabbage changes from R5.00 to R3.00, while holding the other economic variables constant. As shown by the Gross margin values, it is only profitable to produce Chinese cabbage at high production level in Case 2, as compared to Case 1 where it could be produced profitably at both medium and high production levels. A robust sensitivity analysis with multiple changes in economic factors will enrich the study, however, this is suggested as an area of further investigation.

Table 4. Sensitivity analysis for fertilizer experiment

\begin{tabular}{|c|c|c|c|c|c|c|}
\hline & \multicolumn{3}{|c|}{$\begin{array}{c}\text { Case } 1 \\
\text { (Current price of Chinese cabbage }=\mathbf{R 5 . 0 0} \text { per } \mathrm{kg} \text { ) }\end{array}$} & \multicolumn{3}{|c|}{$\begin{array}{c}\text { Case } 2 \\
\text { (Future price of Chinese cabbage }=\mathbf{R 3 . 0 0} \text { per kg) }\end{array}$} \\
\hline & $\mathrm{LP}\left(10.1 \mathrm{tha}^{-1}\right)$ & $\operatorname{MP}\left(26.1 \mathrm{tha}^{-1}\right)$ & $\operatorname{HP}\left(44.5 \mathrm{tha}^{-1}\right)$ & $\mathrm{LP}\left(10.1 \mathrm{tha}^{-1}\right)$ & $\operatorname{MP}\left(26.1 \mathrm{tha}^{-1}\right)$ & $\operatorname{HP}\left(44.5 \mathrm{t} \mathrm{ha}^{-1}\right)$ \\
\hline Gross income (R/ha) & $\mathrm{R} 40,400.00$ & R104,400.00 & R178,000.00 & $\mathrm{R} 24,240.00$ & R62,640.00 & R106,800.00 \\
\hline Total variable costs $(\mathbf{R} / \mathbf{h a})$ & $\mathrm{R} 57,064.19$ & $\mathrm{R} 75,308.01$ & $\mathrm{R} 95,192.93$ & $\mathrm{R} 57,064.19$ & $\mathrm{R} 75,308.01$ & $\mathrm{R} 95,192.93$ \\
\hline Gross margin (R/ha) & $\underline{\underline{\mathrm{R}} 16,664.19}$ & $\underline{\mathrm{R} 29,091.99}$ & $\underline{\mathrm{R} 82,807.07}$ & $\underline{-\mathrm{R} 32,824.19}$ & $\underline{-\mathrm{R} 12,668.01}$ & $\underline{\mathrm{R} 11,607.07}$ \\
\hline \multicolumn{7}{|c|}{ Marginal rates of return } \\
\hline & \multicolumn{3}{|c|}{$\mathrm{LP}$ to $\mathrm{MP}=350.8 \%$} & \multicolumn{3}{|c|}{$\mathrm{LP}$ to $\mathrm{MP}=210.5 \%$} \\
\hline & \multicolumn{3}{|c|}{$\mathrm{MP}$ to $\mathrm{HP}=370.1 \%$} & \multicolumn{3}{|c|}{ MP to $\mathrm{HP}=222.1 \%$} \\
\hline
\end{tabular}

Note. $\mathrm{LP}=$ Low production; $\mathrm{MP}=$ Medium Production; $\mathrm{HP}=$ High Production.

\subsection{Cost Distribution Analysis}

A general overview of the variable costs, indicate that a substantial amount of money is required for commercial production of Chinese cabbage. A total amount of R75,308.01 ha $\mathrm{ha}^{-1}$ and R95,192.93 ha $\mathrm{ha}^{-1}$ is needed to cover total variable costs for medium and high production levels respectively.

In order to analyse the distribution of costs of production, costs were divided into three major categories, which are input costs, tractor-running costs and labour costs. Inputs costs included the costs of vermiculite, hygromix, water, electricity, seeds, seedling trays and fertilizer. The differences in the input costs for different production levels vary mainly due to different costs of fertilizer. As shown on Table 2, the input costs for low, medium and high production levels as a ratio of total variable costs (TVC) are $46.3 \%, 43.2 \%$ and $41.4 \%$ respectively. These values show that the input costs decrease as the level of production increase. These results support the findings by Olujide and Oladele (2007) on the study of economics of Amaranthus production. Tractor-running costs comprised of the costs of ploughing, discing, rotovating and row making. The monetary value of the tractor-running costs is the same for the three production levels $\left(\mathrm{R} 4,500.00 \mathrm{ha}^{-1}\right)$, however when measured against the total variable costs, they are greater at low production level. Labour costs included seedling preparation, tractor driver, transplanting, fertilization, irrigation, weed management and harvesting labour. Labour costs for medium (50.8\%) and high (53.8\%) production levels account for more than half of the total 
variable costs. These results indicate that production of Chinese cabbage is labour-intensive, particularly during transplanting and harvesting, as these activities are performed manually. Weed management labour costs were minimal relative to transplanting and harvesting labour costs because Chinese cabbage is cultivated during the winter season, where several weeds fail to survive winter temperatures.

\section{Conclusion and Recommendations}

The study analysed the profitability and costs of commercial production of Chinese cabbage under irrigation in South Africa. The results of the study show that the use of different levels of fertilizer in production influences the yield level of Chinese cabbage. Limited use of fertilizer, particularly Nitrogen results in lower fresh leaf yield, which consequently leads to negative gross margins (loss). However, it is profitable to produce Chinese cabbage at medium and high production levels, where the latter is preferred as it yields relatively higher gross margin. It is notable that the right mix of fertilizer (NPK) should be applied in production because an increase in one nutrient, without increasing the other nutrients does not guarantee an increase in yield. In terms of costs, different levels of fertilizer that were applied in production have an effect on the variable costs. Thus, the variable costs increased with an increase in fertilizer (NPK) application. Nonetheless, the increase in costs of production were offset by the increase in gross income, as the level of production changes from low to medium and finally to high.

It can be deduced from the results of the study that high production level of Chinese cabbage brings about the highest monetary gains. Further, the study identified the differences between the agronomic optimum and the economic optimum. Therefore, an interdisciplinary evaluation approach (agronomy and economics) used in the study assisted in identifying production recommendations that align to farmer needs and priorities of maximising economic returns from production activities.

The study concludes that farmers willing to reap high monetary values from producing Chinese cabbage should aim to produce high yields which also are influenced by increased use of fertiliser most particularly increased nitrogen levels. Nonetheless, since only average yield and prices were utilised in the study, there is an opportunity to analyse the study further using sensitivity analysis. A sensitivity analysis is useful for testing a given recommendation with given changes in certain variables. For example, the sensitivity analysis will be useful in identifying changes in profitability resulting from different input and product prices, other than the ones used in the study. Sensitivity analysis will be explored in another article.

Based on the yield and profitability results of the study, commercialization of Chinese cabbage is recommended. The crop offers favourable yield $\left(44.5 \mathrm{t} \mathrm{ha}^{-1}\right)$ and gross margin (R82,807.07 ha $\left.\mathrm{ha}^{-1}\right)$ as compared to one of the most common leafy vegetables in South Africa, spinach which offers a yield of $20 \mathrm{t} \mathrm{ha}^{-1}$ and a gross margin of $\mathrm{R} 43$ 368,02 $\mathrm{ha}^{-1}$. When compared with white cabbage (yield, $60 \mathrm{t} \mathrm{ha}^{-1}$; gross margin, R38,436.54 ha ${ }^{-1}$ ), Chinese cabbage has a higher gross margin despite the high yield obtained from white cabbage (KwaZulu-Natal Department of Agriculture and Rural Development, 2017). Besides the yield and profit benefits, Chinese cabbage brings along nutritional benefits and variety in the meals. In order to realise these benefits, there is need for promoting and raising awareness of the crop. The following recommendations are made:

- Collaboration of private and public institutions in supporting and implementing Nutrition Education Intervention Programmes which promote consumption of healthy and indigenous crops.

- $\quad$ Production of Chinese cabbage can be subsidized in order to encourage increased production by farmers and to make prices affordable to poor consumers.

- $\quad$ Support for creativity amongst farmers when they package and market Chinese cabbage. Farmers and other players along the value chain can consider value addition and product development from the crop.

\section{References}

African Centre for Biodiversity. (2017). Towards national and regional seed policies in Africa that recognise and support farmer seed systems (Policy discussion document).

ARC (Agricultural Research Council). (2018). Indigenous/Traditional African Leafy Vegetables. Retrieved September 26, 2018, from http://www.arc.agric.za/arc-vopi/pages/crop\%20science/indigenous-crops.aspx

DAFF (Department of Agriculture, Forestry and Fisheries). (2013). Most common indigenous food crops of South Africa. Retrieved November 15, 2017, from http://www.nda.agric.za/docs/Brochures/Indigfoodcrps.pdf

DAFF (Department of Agriculture, Forestry and Fisheries). (2018). Resource centre. Retrieved September 26, 2018, from https://www.daff.gov.za/daffweb3/resource-centre

Debertin, D. L. (2012). Agricultural Production Economics (2nd ed.). Lexington: Amazon Createspace. 
Dobermann, A., \& Nelson, R. (2013). Opportunities and Solutions for Sustainable Food Production. Background paper for the High-Level Panel of Eminent Persons on the Post-2015 Development Agenda. Sustainable Development Solutions Network.

Ebert, A. W. (2014). Potential of underutilized traditional vegetables and legume crops to contribute to food and nutritional security, income and more sustainable production system. Sustainability, 6, 319-335. https://doi.org/10.3390/su6010319

Elferink, M., \& Schierhorn, F. (2016). Global Demand for Food Is Rising. Can We Meet It? Harvard Business Review. Retrieved November 14, 2017, from https://hbr.org/2016/04/global-demand-for-food-is-rising-canwe-meet-it

Hughes, J. d'A., \& Ebert, A. W. (2013). Research and Development of Underutilized Plant Species: The Role of Vegetables in Assuring Food and Nutritional Security. In F. Massawe, S. Mayes, \& P. Alderson (Eds.), Proceedings of the 2nd International Symposium on Underutilized Plant Species: Crops for the Future-Beyond Food Security (pp. 79-91). International Society for Horticultural Sciences (ISHS), Korbeek-Lo, Belgium. https://doi.org/10.17660/ActaHortic.2013.979.5

Keatinge, J. D. H., Yang, R. Y., Hughes, J. d'A., Easdown, W. J., \& Holmer, R. (2011). The importance of vegetables in ensuring both food and nutritional security in attainment of the Millennium Development Goals. Food Science, 3, 491-501. https://doi.org/10.1007/s12571-011-0150-3

Khapayi, M., \& Celliers, P. R. (2016). Factors limiting and preventing emerging farmers to progress to commercial agricultural farming in the King William's Town area of the Eastern Cape Province, South Africa. South African Journal of Agricultural Extension, 44(1), 25-41. https://doi.org/10.17159/2413-3221/ 2016/v44n1a374

Kibirige, D., Chiguvare, T., \& Masika, P. J. (2014). Enterprise Budgets of Selected Vegetable Grown by Small-scale Commercial and Subsistence Farms in the Eastern Cape Province of South Africa. IOSR Journal of Agriculture and Veterinary Science, 7(12), 60-70. https://doi.org/10.9790/2380-071226070

KwaZulu-Natal Department of Agriculture and Rural Development. (2017). Enterprise Budget: Vegetable crops (COMBUDS).

Macaskill, C. (2017). Indigenous food crops. The Agri Handbook. Johannesburg: SAHB Publishing.

Manyelo, K. W., van Averbeke, W., \& Hebinck, P. (2015). Smallholder irrigators and fresh produce street traders in Thohoyandou, Limpopo province, South Africa. In P. Hebinck, J. D. van der Ploeg, \& S. Schneider (Eds.), Rural development and the construction of new markets (pp. 131-148). London: Routledge.

Maoba, S. (2016). Production performance and profitability analysis of small scale layer projects supported through CASP in Germiston Region, Gauteng Province. South African Journal of Agricultural Extension, 44(1), 42-49. https://doi.org/10.17159/2413-3221/2016/v44n1a368

Maseko, I., Beletse, Y. G., Nogemane, N., du Plooy, C. P., Musimwa, T. R., \& Mabhaudhi, T. (2017). Productivity of non-heading Chinese cabbage (Brassica rapa subsp. chinensis) under different agronomic management factors. South African Journal of Plant and Soil, 34(4), 275-282. https://oi.org/10.1080/ 02571862.2017 .1295324

Maseko, I., Mabhaudhi, T., Tesfay, S., Araya, H. T., Fezzehazion, M., \& du Plooy, C. P. (2018). African Leafy Vegetables: A review of status, Production and utilization in South Africa. Sustainability, 10(16), 1-16. https://doi.org/10.3390/su10010016

Mavengahama, S. (2013). The Contribution of Indigenous Vegetables to Food Security and Nutrition within Selected Sites in South Africa (PhD Thesis, Stellenbosch University, Cape Town, South Africa).

Mushaphi, L. F., Dannhauser, A., Walsh, C. M., Mbhenyanec, X. G., \& van Rooyend, F. C. (2017). The impact of a nutrition education programme on feeding practices of caregivers with children aged 3 to 5 years in rural Limpopo Province, South Africa. South African Journal of Clinical Nutrition, 30(4), 101-108. https://doi.org/10.1080/16070658.2017.1322823

Ocneanu, L., \& Bucşă, R. C. (2014). Economy Transdisciplinarity Cognition, Vol. 17, Issue 2/2014, pp84-92

Okorogbona, A. O. M., van Averbeke, W., \& Ramusandiwa, T. D. (2011). Growth and yield response of Chinese cabbage (Brassica rapa L. subsp. chinensis) as affected by nutrient availability in air-dried and pulverized different types of animal manure using low biological activity soil. World Journal of Agricultural Sciences, 7(1), 1-12. 
Olujide, M. G., \& Oladele, O. I. (2007). Economics of Amaranthus production under different NPK Fertilizer Regimes. Bulgarian Journal of Agricultural Science, 13, 225-229.

Onyango, M.A. (2002). Effect of nitrogen on leaf size and anatomy in onion (Allium cepa L.). East African Agriculture and Forestry Journal, 68, 73-78. https://doi.org/10.4314/eaafj.v68i2.1779

Podsedek, A. (2007). Natural antioxidants and antioxidant capacity of Brassica vegetables: A review. LWT Food Science and Technology, 40, 1-11. https://doi.org/10.1016/j.lwt.2005.07.023

Rural Solutions SA. (2013). Farm gross margin and enterprise planning guide "A gross margin template for crop and livestock enterprises". SAGIT and Grains Research \& Development Corporation. Retrieved April 5, 2018, from https://grdc.com.au/_data/assets/pdf_file/0024/141927/farm-gross-margin-and-enterpriseplanning-guide-2013.pdf.pdf

Stamp, P., Messmer, R., \& Walter, A. (2012). Competitive underutilized crops will depend on the state funding of breeding programmes: An opinion on the example of Europe. Plant Breeding, 131, 461-464. https://doi.org/ 10.1111/j.1439-0523.2012.01990.x

Tilman, D., Balzer, C., Hill, J., \& Befort, B. L. (2011). Global food demand and the sustainable intensification of agriculture. Proceedings of the National Academy of Sciences, 108(50), 20260-20264. https://doi.org/ 10.1073/pnas. 1116437108

Tshikalange, T. E., \& van Averbeke, W. (2006). The cultivation of Brassica rapa L. subsp. Chinensis in Vhembe, Limpopo Province, South Africa. Proceedings of International Symposium on the Nutritional Value and Water Use of Indigenous Crops for improved Livelihoods, University of Pretoria, Pretoria, South Africa.

van Averbeke, W., \& Netshithuthuni, C. (2010). Effect of irrigation scheduling on leaf yield of non-heading Chinese cabbage (Brassica rapa L. subsp. chinensis). South African Journal of Plant and Soil, 27, 322-327. https://doi.org/10.1080/02571862.2010.10640001

van Averbeke, W., Chabalala, M. P., Okorogbona, A. O. M., Ramusandiwa, T. D., Azeez, J. O., \& Slabbert, M. M. (2012). Plant nutrient requirements of African leafy vegetables. In A. Oelofse \& W. van Averbeke (Eds.), Nutritional value and water use of African leafy vegetables for improved livelihoods (pp. 173-209, WRC Report No. TT535/12). Pretoria: Water Research Commission.

van Averbeke, W., Juma, K. A., \& Tshikalange, T. E. (2007). Yield response of African leafy vegetables to nitrogen, phosphorus and potassium: The case of Brassica rapa L. subsp. chinensis and Solanum retroflexum Dun. Water $S A$, 33, 355-362. https://doi.org/10.4314/wsa.v33i3.180595

van Jaarsveld, P., Faber, M., van Heerden, I., Jansen van Rensburg, W., \& van Averbeke, W. (2014). Nutrient content of eight African leafy vegetables and their potential contribution to dietary reference intakes. Journal of Food Composition and Analysis, 33, 77-84. https://doi.org/10.1016/j.jfca.2013.11.003

Van Wyk, B. E. (2005). Food plants of the World. Pretoria: Briza Publications.

Visagie, S. E., \& Ghebretsadik, A. H. (2005). Modelling risk in farm planning. Agrekon, 44(4), 561-585. https://doi.org/10.1080/03031853.2005.9523728

\section{Copyrights}

Copyright for this article is retained by the author(s), with first publication rights granted to the journal.

This is an open-access article distributed under the terms and conditions of the Creative Commons Attribution license (http://creativecommons.org/licenses/by/4.0/). 